\title{
Daniel Acuña
}

Pontificia Universidad Católica de Chile

\section{H. U. von Balthasar y Alberto Magno. Apuntes sobre sus confluencias en torno al quehacer teológico}

Con mucho gusto he accedido a la invitación a ofrecer una comunicación sobre la implicancias que puede tener para la teología la concepción de la misma que surge de la doctrina del doctor universalis, san Alberto Magno (1), en una iluminadora confrontación con el pensamiento balthasariano. Aun cuando no encontramos un estudio más amplio dedicado al obispo dominico, Balthasar menciona sus aportes en el campo de la estética trascendental, desde el momento en que en él se dan cita las doctrinas aristotélica de la armonía y la plotiniana de la luz (a través de Dionisio) (2). Con todo, intentaremos, a partir de la cuestión planteada por Alberto Magno en su obra Super mysticam theologiam Dionysii (SMT) (3) sobre el theologicum negotium, descubrir algunas confluencias importantes de ambos teólogos. Rastrearemos algunas betas de esta temática en la Trilogía y tendremos a la vista algunos estudios de Balthasar alusivos al tema (4). De ello extraeremos algunas conclusiones.

(1) Sobre la figura y obra de Alberto Magno se puede consultar: G. Fraile, Historia de la Filosofía, t. II( $\left.2^{\circ}\right)$, Madrid, 1986, 232-258; I. Craemer-Ruegenberg, Alberto Magno, Barcelona 1985, 11-35; A. de Libera, Albert le Grand et la Philosophie, París, 1990, 7-36. Datos sobre la vida y obra de san Alberto Magno ya es posible encontrarlos en el siglo XIV y XV: Enrique de Herford, Liber de Rebus Memorabilius (c. 1335), A. Potthast (ed.), Göttingen 1859; Luis de Valladolid, Tabula Alberti Magni (1414), en Analecta (Sacri) Ordinis Praedicatorum, 20 (1932), 752-761; Rodolfo de Nijmegen, Legenda Alberti Magni (c. 1488), H. C. Scheeben (ed.), Colonia 1928. Se pueden consultar con provecho: M. Viller, Albert le Grand (Saint), en Dictionnaire de spiritualité, ascetiqué et mystique, doctrine et histoire, I, Paris 1937-1995, 217-283; P. Simon, Albert der Grosse, en Theologische Realenzyklopädie, II, Berlin 1978, 177-184; G. Binding-P. Dilg, Albertus Magnus, en Lexikon des Mittel Alters, I, München-Zürich 1980, 294-299; I. Sturlese, Albert le Grand (Saint), en Dictionaire Encyclopédique du Moyen Âge, I, Paris 1997, 30-31.

(2) Cf H. von Balthasar, Gloria. Una estética teológica, Vol. 4, Metafísica. Edad Antigua, Madrid 1987, 346-348.

(3) El texto latino de la obra de Alberto la encontramos en la Edición Coloniense: Opera Omnia, Institut Albertus Magnus-Bonn (Editio Coloniensis), Colonia 1951ss, vol. XXXVII/2. La traducción al español de los textos que transcribiremos está tomada de la reciente edición de A. Meis, Alberto Magno. Sobre la Teología Mística de Dionisio. Super Mysticam Theologiam Dionysii, Santiago de Chile 2008.

(4) Cf. H. U. von Balthasar, Teología y santidad, en Ensayos Teológicos I. Verbum Caro, Madrid 1964, 235-268; Theologie und Spiritualität, en Gregorianum 50 (1969) 571-586. 
Ambos teólogos son metafísicos: Alberto permite y promueve, como es sabido, el ingreso de la ontología aristotélica y también las expresiones árabes en la reflexión cristiana, posibilitando así no sólo una distinción más clara y sana de los ámbitos filosófico y teológico, sino que puso las bases para un desarrollo profundo de la sistemática del dogma. El teólogo suizo, recibiendo de la tradición eclesial la doctrina tomaseana del esse (5), de alguna manera despliega a su modo y genialmente esta ontología en su Trilogía ofreciéndonos, siete siglos después del santo dominico, una concepción de la teología de tipo sapiencial, kerygmática y dialógica (6). Pues bien, como veremos, la distancia y los contextos no nos impiden un cotejo enriquecedor en un punto tan capital, pero a mi parecer a veces demasiado postergado, como es el de la unidad entre conocimiento y vida creyente del teólogo en su quehacer o negotium que le es propio.

En primer lugar, expondré las líneas fundamentales de lo que Alberto Magno entiende por theologicum negotium en su SMT, tema fundamental de mi tesis de grado de Magíster presentada en la Facultad de Teología de esta Universidad en abril del presente año (7). En este trabajo de comentario a la Teología Mística del Pseudo Dionisio Areopagita (1250) encontramos una síntesis muy original e interesante sobre las relaciones entre reflexión científica sobre la fe y vida de unión con Dios, es decir sobre la vía mística de la teología. Ahora bien, en la elaboración del SMT Alberto utiliza la traducción de Juan Sarraceno (h.1100) (8). Anteriormente ya había explicado las otras obras de Dionisio Areopagita: De caelesti hierarchia, De ecclesiastica hierarchia (1248) y De divinis nominibus (1249-1250) (9), posiblemente a partir de la traducción de Juan Scoto Eriúgena. La interpretación de la Teología Mística descansa así sobre una doble base: por una parte se apoya en el conjunto del Corpus dionysiacum y así prepara la exposición de un texto difícil de interpretar y que con derecho se concibe como la clave de la visión del Areopagita y, por otra, los grandes discernimientos sobre el intelecto ofrecidos por la noética grecoárabe que le servirá para dar razón al procedimiento negativo y apofático tan poco tomado en cuenta en la teología latina.

(5) Sin duda que la doctrina sobre el ser es una mediación que le es útil a Balthasar para realizar en cada uno de sus desarrollos teológicos un vivo intercambio entre filosofía y teología. Esta mediación filosófico-teológica se hace posible precisamente por la misma naturaleza del esse: es la primera semejanza de Dios en el mundo, es decir, la misma gloria de Dios difundida en cada unos de los seres, los que continuamente remiten a su fundamento supremo y divino. Cf. E. Pérez Haro, El misterio del ser. Una mediación entre filosofía y teología en Hans Urs von Balthasar, Barcelona 1994, 43 ss.

(6) Cf. A. Moda, Hans Urs von Balthasar, un'esposizione critica del suo pensiero, Bari 1976, 206-209.

(7) Cf. D. Acuña Burgos, El theologicum negotium según el Super mysticam theologiam Dionysii de San Alberto Magno. Estudio de la racionalidad propia y de la unión con Dios en la teología, Santiago de Chile 2008.

(8) Los editores de la Edición Coloniense están de acuerdo en que la traducción utilizada para el Comentario de Alberto a la Teología Mística y Los nombres de Dios de Dionisio es la que le ofrece Juan Sarraceno ("nova" translatio) (cf. Alberto Magno, Super Dionysium de Divinis Nominibus, (SDN), en Editio Coloniensis, vol. XXXVII/1, Prolegomena, xviiis. Además, leemos en I, 47s: "Intendimus autem exponere novam translationem Iohannis Sarraceni, quia melior est").

(9) Cf. H.-F. Dondaine, Date du Commentaire de la Hiérarchie céleste de saint Albert le Grand, en Recherches de Théologie ancienne et médiévale 20 (1953) 315-322. 
Se sabe que los teólogos contemporáneos a Alberto mantenían marginada la oscura obra del Areopagita. Sin embargo, su vasta competencia filosófica le permite discernir las principales posiciones propias respecto de la noética neoplatónica, haciendo las adaptaciones y armonizaciones necesarias en favor de una teología de la revelación bíblica. Por lo mismo, es que desde los primeros párrafos del SMT nuestro autor desea mostrar a la teología mística dionisiana como una doctrina que cabe con total perfección en los marcos científicos de la teología de la época. Los "cuatro aspectos" que expone (quattor possunt extrahi) (10) abriendo el Comentario son la puerta epistemológica y metodológica por la cual se entra en toda ciencia (11). Además, el vocabulario presente da cuenta de esta cualidad científica de la teología mística, para lo cual Alberto hará uso libre, aunque sin dejar de ser crítico, de la nomenclatura aristotélica que le ha parecido del máximo rigor. Lo místico y sobrenatural se abre paso también desde este basamento racional poderoso proporcionado por la obra aristotélica.

Según estas premisas, ¿cuál es la génesis -y en ella se comprende el contenido y el sentido- según Alberto del trabajo teológico, el theologicum negotium? La afirmación directa más importante sobre el theologicum negotium la encontramos en un pasaje (I, 455, 88-456, 2) al modo de una apretada síntesis. El texto es el siguiente:

(10) Cf SMT I, 453, 7.

(11) Una síntesis del contenido de los capítulos del SMT puede ser la siguiente. En el primer capítulo Alberto expone las grandes líneas de la Teología Mística de Dionisio de modo sistemático. Una primera parte introduce al lector en los aspectos formales de esta ciencia o doctrina: "modus, materia, auditor et finis", los cuales definen desde el inicio el sentido y alcance del Comentario. Luego de justificar el título de "mystica" que se da a esta doctrina que se dice ser ciencia, anuncia la división del libro que comenta dando inicio al Comentario mismo, explicando la Oración de gran densidad que en el fondo abre el libro (accedamus ad orationem). Finalmente, dedica la mayor parte del capítulo a explicar exegéticamente el modo de aprender la ciencia o teología mística. Quedando planteado el sentido de unión con Dios y por ende el sentido salvífico de la teología mística, Alberto desarrolla este tema en el segundo capítulo de la obra. Describe aquí la importante y capital naturaleza intelectiva de la unión: "ideo in isto capitulo determinat modum quantum ad unitionem, quomodo scilicet oportet per intellectum uniri deo et voce laudare ipsum” (II, 465, 2-11). Queda establecido, además, que el método apofático dionisiano expuesto en la Teología Mística es el indicado para progresar hacia la unión con Dios. Alberto propone, además, otras cuestiones que complementan las explicaciones ya hechas y que tienen que ver con la índole del conocimiento contemplativo, precisiones sobre el modo de la unión intelectiva y sobre las relaciones entre las afirmaciones y negaciones. En el tercer capítulo el obispo dominico comenta las afirmaciones dionisianas sobre las "teologías afirmativas" y las "teologías negativas", sus mutuas implicancias y su presencia en las obras La teología simbólica, Las representaciones divinas y Los nombres divinos. Hará, por otra parte, una aplicación de tales métodos a la teología trinitaria y en particular a la cristología. El cuarto y el quinto capítulo del SMT vienen a ser un comentario pormenorizado de las remociones divinas por las cuales se ingresa a la divina tiniebla. En el cuarto capítulo, se exponen las remociones de lo sensible y en el capítulo quinto - explica Alberto- "se pretende remover de Dios todo lo inteligible". Para ello expone de modo muy original y profundo el sentido de los nombres o denominaciones sobre Dios y sus propios límites, después de lo cual comenta las negaciones de las formas inteligibles, para rematar removiendo no sólo las afirmaciones, sino también las mismas negaciones debido al excessus del Ser divino que es inefable: "Et ideo neque negationes neque affirmationes pertingunt ad sufficientiam laudis ipsius..." (Cf. también la síntesis sobre la estructura del SMT en la edición de A. Meis anteriormente citada: 34s). 
"El modo, sin embargo, del que enseña lo divino es para que implore por la oración la verdad de las cosas divinas, que deben ser transmitidas a otros, porque en todo negocio teológico hay que comenzar desde la oración” (12).

Cuando desea exponer la división del libro que comenta, Alberto hace una compleja disquisición centrándose, según el vocabulario empleado, en la cuestión metodológica: en una sección que va desde 455, 65 a 456, 5 se ha utilizado 14 veces el vocablo modus, frecuencia que confirma nuestra hipótesis. De este modo se sitúa el theologicum negotium en el marco del método según sus formas y aplicaciones. Es así que las diversas divisiones que nuestro autor distingue, teniendo siempre a la vista el modus, desembocan en una sentencia que busca desentrañar el contenido del modus docentis divina. Al afirmar que "el modo del que enseña lo divino" es la impetración por la oración la verdad divina, revela la forma mentis de Alberto para quien el theologicum negotium es ante todo el resultado de la acción divina en el hombre que teologiza, siendo éste movido a adentrarse en el Misterio divino. Tenemos, entonces, que la impetración por la oración da un sentido específico a la instrucción: enseñar es recibir como don la intelección de las cosas divinas, postulándose de este modo un "maestro" de quien se recibe el conocimiento impetrado (13). También nos recuerda Alberto que la necesidad de iniciar el theologicum negotium por la plegaria se impone por la "sublimidad de la doctrina" (propter altitudinem doctrinae). En la oración, por tanto, se pide ser llevado por Dios (y a Dios) (precamur nos fieri a deo) hasta la tiniebla mística (in hac caligine) "en la que Dios se encuentra" y en la que "no-viendo" y "no-conociendo" de algún modo se le ve y se le conoce (14). Como Dios o lo divino es aquello que se busca contemplar en la teología, y El est super omnem, la oración es el inicio y la condición del ascenso y progreso.

El modus docentis de la teología mística deja, por lo tanto, inclinado el plano hacia la acción de la gracia en el hecho del theologicum negotium. La veritas divina "se encuentra por sobre nuestra ciencia" y sólo es posible alcanzarla por el ejercicio

(12) SMT I, 455, 88-456, 2: "Modus autem docentes divina est, ut per orationem veritatem divinorum impetret, quam tradere aliis debet, quia in omni theologico negotio incipiendum est ab oratione".

(13) En el SDN Alberto se había explayado sobre el significado de la oración para alcanzar el auténtico conocimiento de los nombres divinos. Al comentar el capítulo tercero de la obra de Dionisio, afirma de qué modo la oración es el "material" o "contenido" (instrumentum) del que está hecha la ciencia de los nombres divinos: la oración es su medio propio y no así la argumentación (III, 101, 11-16: "Consequenter in hoc TERTIO CAPITULO determinat de eo quod est quasi instrumentum accipiendi divina nomina, scilicet de oratione, cum omnis scientia habeat proprium instrumentum, huius autem instrumentum doctrinae non argumentatio, sed oratio est"). El "poder de la oración -afirma Albertoes el instrumento para llegar al conocimiento de los nombres divinos" (III, 101, 23-25: "Quae sit virtus orationis, quae est instrumentum deveniendi in cognitionem divinorum nominum”). La oración es el medio apropiado para alcanzar el conocimiento de Dios. Es decir, para examinar todo lo que a El se refiere es necesario hacer oración invocando primero a Dios (cf III, 102, 37ss). La oración es necesaria, entonces, no sólo en la ciencia de los nombres divinos, sino en la misma ciencia teológica (cf III, 104, 83-91).

(14) SMT I, 465, 17-25: "Et sicut in superiori capitulo ponens modum perceptionis incepit ab oratione propter altitudinem doctrinae, ita et hic, dicens: Precamur nos fieri a deo in hac caligine in qua est deus, obscura quoad nos, superlucenti in se, et precamur in ipso non videre et non cognoscere, idest in hoc ipso, dum omnes naturales nostrae cognitiones vacant, per non-videre et ignorare sicut per quandam viam videre et cognoscere eum qui est super omnem etc., scilicet deum”. 
de la oración que despierta la benignitas divina. Este será el "ad oppositum" que finalmente decide la cuestión: ninguna ciencia sobre Dios puede recibirse "si su benignidad no se inclina para que se infunda [la verdad divina] en nosotros" (15). Por su parte, la solutio confirma y profundiza esta afirmación ahora en la línea de Bernardo de Claraval y su De consideratione: "para captar lo divino más bien se llega orando que discutiendo (disputando)" (16).

Para el maestro dominico la interpretación del fondo de la teología mística dionisiana antes descrita, se ubica precisamente en la línea agustiniana. En efecto, la verdad divina buscada (quae hic quaeritur) es la misma Verdad que Agustín llama magister interior, sin cuya acción iluminadora "se frustra toda búsqueda" de la razón creyente (17). Es que se está reconociendo, siguiendo a Agustín, la insuficiencia de la razón filosófica y la necesidad de la fe para aprehender la Verdad divina: algunos querrían "comprender por la razón humana lo que la mente piadosa (pia mens) necesita aprender por la vivacidad de la fe" (18).

Esta condición de donación del theologicum negotium otorga a la teología su doble carácter de scientia y sapientia como sabiduría participada por Dios. Con ello, el santo dominico ha hecho una transposición de la filosofía primera de Aristóteles quien a la metafísica llama "sabiduría primera" (19), pues los saberes de todas las demás ciencias le están subordinadas y ella juzga a todas. La teología es sabiduría primera. La ciencia de las Sagradas Escrituras, que es la teología, es "superior a todas las demás ciencias" (20), por lo que llega a ser sabiduría suprema. Cuanto más que ella tiene como Causa eficiente y como causa final a Dios mismo, es decir la intelección divina. Es decir, en la cima del theologicum negotium "el intelecto contemplativo es absorbido por la luz divina" (21), y así la perfección del intelecto obrada por la luz divina es la máxima ciencia y sabiduría posibles. Pero también recordemos que ya en el siglo XIII se habla en sentido agustiniano (doctrina anterior a Dionisio entonces) de

(15) SMT I, 456, 19-24: “(3) Ad oppositum: veritas, quae est supra scientiam nostram, non potest accipi, nisi sua benignitas inclinetur ad hoc quod infundat se nobis; cum igitur talis sit veritas, quae hic quaeritur, et divina benignitas non inclinetur nisi oratione, videtur, quod oratio debeat esse modus docentis secundum hanc doctrinam”. Cf. I, 456, 29-30.

(16) SMT I, 456, 25-27: "Solutio: Dicendum, quod, sicut GREGorIUs dicit in PRINCIPIO MORALIUM, ad divina capienda magis orando quam disputando pervenitur". En el De consideratione Bernardo afirma: "Quaerendus adhuc fuerat, qui nec satis adhuc inventus est nec quaeri nimis potest; at orando forte quam disputando dignius quaeritur et invenitur facilius. Proinde is sit finis libri, sed non finis quaerendi" (De consideratione ad Eugenium Papam, en Sancti Bernardi Opera, III, Roma 1963, 493, 23-25).

(17) SMT I, 456, 28-32: "Quia cum divina veritas superet nostram rationem, nos ex nobis eam manifestare non possumus, nisi ipsa se dignetur infundere; ipsa enim est magister interior, sine quo frustra laborat magister exterior, ut dicit AUGUSTINUs".

(18) SMT I, 458, 38-45: "Unde etiam PHILOSOPHI dicunt, quod motor primus est proportionatus mobili primo; sed putant se posse scire eum qui ponit etc., scilicet deum, ea cognitione quae est secundum ipsos, idest per principia rationis, sicut dicitur de AUGUSTINO, quod tumens inani philosophia volebat humana ratione comprehendere, quod pia mens vivacitate fidei nititur apprehendere”.

(19) Aristóteles, Metafísica, I, c. 2 (982 a 14-16), en Aristotelis. Metaphysica, W. Jaeger (ed.), Oxford 1992, 4.

(20) Alberto Magno, Summa theologiae, Editio Coloniensis, vol XXXIV/1, I, Prologus, 1, 5-8: “'Mirabilis facta est scientia tua ex me; confortata est, et non potero ad eam'. In hac auctoritate sex notantur, quibus scientia sacrarum litterarum omnes excellit alias scientias".

(21) SMT I, 463, 50-51: "Intellectus contemplativus absorbetur in divino lumine". 
ratio inferior, es decir la ciencia, y ratio superior, es decir la sabiduría propiamente dicha (22). Conforme a esta distinción, la teología como sabiduría adquiere un sentido de seguimiento y conversión del alma a Dios gracias a la fides quaerens intellectum del teólogo y de la teología como tal. Mirado con este prisma, en el quehacer teológico albertino scientia y sapientia son ámbitos de un mismo campo de inteligibilidad: la luz de la fe, como luz recibida, es conocimiento sobrenatural que perfecciona el intelecto en la unión plena con Dios en el acto contemplativo.

La acción de Dios como "gracia iluminante" otorga la coherencia interna al theologicum negotium en esta especie de atmósfera dionisiana del misterio de la iluminación (23), en cuanto que hace del oficio teológico una dinámica que se despliega como iluminación graciosa y santificante del auditor u oyente de la teología. Hay que recordar que así lo había establecido Dionisio al equiparar la ciencia jerárquica con la santidad: a mayor ciencia (en cuanto cercanía al Dios Inefable) mayor santidad (24).

(22) Cf M.-D. Chenu, La Théologie comme sciencie au XIII siecle, Paris 1957, 93ss.

(23) Dionisio afirma en la Jerarquía celeste: "La jerarquía, pues, tiene por fin lograr en las criaturas, en cuanto sea posible, la semejanza y la unión con Dios. Una jerarquía tiene a Dios como maestro de todo saber y acción. No deja de contemplar su divinísima hermosura. Lleva en sí la marca de Dios. Hace que sus miembros sean imágenes de El bajo todos los aspectos, espejos transparentes y sin mancilla, que refleja el brillo de la luz primera y de Dios mismo. Luego que sus miembros han recibido la plenitud de su divino esplendor, transmiten generosamente la luz, conforme al plan de Dios, a aquellos que le siguen en la escala [...] Así que el nombre de jerarquía designa una disposición sagrada, imagen de la hermosura de Dios, que representa los misterios de la propia

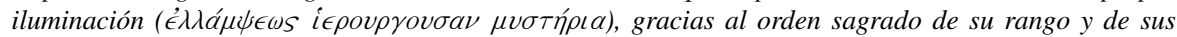
saberes. Se asemeja a la propia fuente y, en cuanto es posible, se configura con su propio origen [...] Por eso, cuando el orden sagrado dispone que unos sean purificados y otros purifiquen; unos sean iluminados y otros iluminen; unos sean perfeccionados y otros perfeccionen, cada cual imitará a Dios de hecho según el modo que convenga a su función propia” (III, 165A-B, en Obras completas del Pseudo Dionisio Areopagita, T. H. Martin-Lunas (ed.), Madrid 1995, 132s; Corpus Dionysiacum, G. Heil-A. M. Ritter (eds), Berlin-New York 1991, II, 17-19).

(24) En la visión religiosa dionisiana de la estructura jerárquica del universo el conocimiento produce divinización. Si los grados de ciencia son diversos conforme a los diversos lugares ocupados por los órdenes jerárquicos, también en este orden estructural se da que tales grados de ciencia corresponden a los grados de santidad alcanzados. Y lo primero que puede decirse es que si no se puede afirmar que en Dionisio hay una ciencia-virtud como en el socratismo y el platonismo, sí hay cierta correlación con esta noción gracias al concepto ciencia-santidad. Es así que los órdenes más elevados son los más santos y los más avanzados en la ciencia divina: los obispos en la jerarquía sacerdotal, los monjes en la jerarquía de lo iniciados; los órdenes medios e inferiores corresponden a los grados medios e inferiores de la ciencia y la santidad. No deja de ser interesante que para Dionisio unos mismos obstáculos se oponen al progreso tanto de la ciencia como de la santidad. En el plano sensible, la una y la otra se ven retardadas por las pasiones que oscurecen la ciencia y no permiten ingresar en la intimidad divina, atándonos al placer inmediato e impidiéndonos encontrar a Dios (Cf. Pseudo Dionisio Areopagita, La jerarquía eclesiástica, III, 433D-436A, en Obras completas, 214s; Corpus Dionysiacum, II, 85-87). Incluso la ciencia y la santidad no progresan cada vez que se cae en la aceptación de representaciones de Dios y no se logra traspasar el mismo orden simbólico de la Escritura quedándose en el orden conceptual simbólico o dialéctico. Aquí se traiciona la verdadera ciencia que considera la absoluta trascendencia de Dios. Por eso se puede decir que el obstáculo contra la ciencia y la santidad que le es proporcional está en la voluntad correspondiente a cada inteligencia que no querría en definitiva buscar a Dios. Por el contrario, la actitud que permite el progreso es que cada inteligencia reduzca el grado de influencia de los sentidos y las mismas pasiones que la dispersan. Es decir, que pueda descubrir en toda la realidad su fondo "anagógico" (cf R. Roques, L'Univers Dionysien. Structure hiérarquique du monde selon le Pseudos-Denys, Paris 1954, 239s). 
El theologicum negotium en la interpretación de Alberto no puede apartarse del derrotero de la Luz ofrecida y donada, frente a la tentación del racionalismo teológico, tantas veces denunciada en la Edad Media. Lo "teológico" se vive como gracia iluminadora del alma para ascender a la cima de la unión amorosa con el Dios deseado y buscado. Para Alberto como para Dionisio la menesterosidad del theologicum negotium establece un lenguaje tan real como proyectivo del ser mismo del hombre contemplador: su intelecto es "elevado", "robustecido" y capacitado para ver en la no-visión, y en ello ir más allá de sí mismo (excessus) -lo cual es imposible por sus propios medios- y adentrarse en el Misterio de Dios. El Intelecto universalmente agente (25) resulta al teólogo y su oficio como acción elevante y perfeccionante en cuanto actúa en el intelecto agente (y por tanto en su voluntad y afectos) del auditor de la ciencia mística. Se comprende así que en palabras del gran erudito de la obra dionisiana, R. Roques, y yendo al meollo del asunto, el amor divino sea, "en último análisis, la causa común de la ciencia y de la santidad" del teólogo; ellas son indisociables puesto que la unión exige "la agudeza de la mirada interior y su total pureza", es decir, la conexión íntima y total implicación entre la ciencia y la santidad son a la vez un don y una exigencia del amor que los creó (26).

Por último, nos queda afirmar que la síntesis albertiniana del theologicum negotium en el SMT nos ha llevado a comprender que la finalidad salvífica de la ciencia mística (27) hemos de remitirla a todo trabajo teológico, considerando las nociones de unión intelectiva, imitación de Dios y deificación e iluminación de la mente. Para ello encontramos los presupuestos del intellectus fidei en su máxima expresión formal y sistemática en los Commentarii in I-IV Sententiarum y la Summa theologiae. En efecto, en el tr. 1, q. 2 de la Summa Alberto define la teología en los términos de Agustín, para quien "la teología es la ciencia que se refiere a las cosas pertenecientes a la salvación de los hombres" (28). Y cuando responde a las objeciones en la misma

(25) El estudio de la peculiar concepción albertiniana de la causalidad universal de Dios nos ha puesto frente a aquella mediación esencial de la ontología en la teología, sobre todo a partir de la asimilación de la doctrina de la metafísica en cuanto "metafísica del flujo" del Liber de causis presente en el SMT (cf. A. de Libera, Albert Le Grand et la Philosophie, Paris 1990, 117-177). Si hubiese que preguntarse qué nociones asimila para sí del Liber, en términos generales habría que decir que fundamentales son dos (cf. A. de Libera, o. c., 142). La afirmación de que el ser es la primera de las cosas creadas (afirma el Liber: "La primera de las cosas creadas es el ser y ningún otro ha sido creado antes del mismo" (Liber de causis (El libro de las causas). Anónimo, R. Aguila (ed), Bilbao 2001, IV, 37), con la consecuente distinción entre lo que es "por creación" y lo que es "por información", y la afirmación de una univocidad propia de la causalidad divina entendida como "flujo de luz" a partir de la Causa Primera que va a definir como "intelecto universalmente agente" (intellectus universaliter agens) y que desarrolla en su obra De causis et processu universitatis a prima causa (Editio Coloniensis, vol. XVII/2)

(26) Cf. R. Roques, Ibid.

(27) SMT I, 454, 3-12: "Finis autem tangitur in hoc quod dicitur 'salvator'. Non enim finis huius doctrinae est tantum, ut sciamus neque ut solum per opera 'boni fiamus', sicut in ethicis, sed ut ulterius ad aeternam salutem perveniatur, in qua quod hic occultum de deo nobis relinquitur per negationes, sine aliquo velamine et aperte nobis obiciatur. Sap. XV (3): 'Nosse te consummata iustitia est, et scire iustitiam et veritatem tuam radix est immortalitatis'. Gen. XXXII (30): 'Vidi dominum facie ad faciem, et salva facta est anima mea'”.

(28) Alberto Magno, Summa theologiae sive de mirabili scientia Dei. Libri I, Pars I. Quaestiones 1-50A, Editio Coloniensis, vol. XXXIV/1, tr. 1, q. 2, 8, 9-11: "Et dicit AGUSTINUS in libro DE TRINITATE $X I V$, quod theologia est scientia, quae est in rebus ad salutem hominum perinentibus”. 
cuestión 2, desarrolla una interesante argumentación sobre la teología secundum pietatem. En la solutio (29) tenemos que: la teología es secundum pietatem porque "la piedad conduce a la salvación", ya que el mismo Agustín explica que la pietas se refiere al culto de Dios que "perfecciona la fe, la esperanza, la caridad, la oración y el sacrificio".

Pasemos ahora a considerar algunas afirmaciones de Balthasar sobre el conocimiento místico y aquella unidad entre teoría y praxis cristiana en la vida y ser del teólogo, tema muy particular en sus reflexiones.

Lo primero que tenemos que decir es que Balthasar conoce muy bien el pensamiento y la obra del Areopagita, como queda demostrado en su estudio de los "estilos eclesiásticos" de Gloria 2 (30). Para Balthasar, es de tal magnitud el influjo del pensamiento de Dionisio, que se deja percibir, por ejemplo, en el gran cuadro de partida y retorno de la Summa de Tomás de Aquino; e incluso puede considerarse que el Areopagita creó "la atmósfera, la paz y la bienaventuranza honda que Agustín no comunica del mismo modo", lo cual hace de su teología "la presencia más considerable de Asia en el corazón de la teología occidental" (31). No es posible perder de vista, por tanto, que el espíritu de la teología mística de Dionisio es la cima oculta o abiertamente presente en toda afirmación teológica, lo que quiere decir que a partir de esta doctrina no es posible ya la tensión entre dogmática y mística, entre conocimiento de Dios y su experiencia unitiva. En otras palabras, el método propio de la teología mística, el apofático, hecho de negaciones y remociones crecientes, "no es sólo método de pensar, es ya encuentro grávido de experiencia, evento que se realiza ante el misterio del Dios vivo aprehendido en la fe" y, a la vez, en la "total convicción de que más allá de las afirmaciones subsiste intacta la sobreabundancia objetiva de Dios" (32).

En efecto, en la Teológica 2, Balthasar reconoce el lugar de la teología negativa en el desarrollo de la reflexión teológica en el arco que va desde la búsqueda extrabíblica de Dios hasta la del creyente en la revelación bíblica (33). A aquella

(29) Ibid., tr, 1, q. 2, 8, 46-66: “[...] sicut dicitur TIT. I (1), theologia scientia est 'secundum pietatem', hoc est quae non est de scibili simpliciter, ut scibile est, nec de omni scibili, sed secundum quod est inclinans ad pietatem. Piestas autem, ut dicit AUGUSTINUS, cultus dei est, qui perficitur fide, spe et caritate et oratione et sacrificiis. Et hoc modo theologia est scientia de his quae hoc modo ad salutem pertinent. Pietas enim conducit ad salutem [...] Haec etiam saepius mediata fidem nutritunt, ut coalescat, et confortant, ut avertentibus resistat. Et de omnibus his, inquantum huismodi sunt, theologia sunt".

(30) Cf H. U. von Balthasar, Dionisio, en Gloria. Una estética teológica, vol. 2. Estilos eclesiásticos, Madrid 2007, 145-205. Balthasar define su elección: "Por otra parte, no hay en el tiempo de la Iglesia ninguna teología históricamente eficaz que no sea a su vez reflejo de la gloria de Dios. Sólo una teología bella, o sea, una teología que, alcanzada por la gloria Dei, logra a su vez hacerla resplandecer, tiene la posibilidad de incidir en la historia de los hombres, impresionándola y transformándola [...] Con esto queda fijado el tema, que es la gloria de la revelación divina tal como se despliega y se presenta en la dimensión de la teología eclesiástica [...] Hemos escogido teólogos oficiales, en especial los que de entre ellos son capaces de representar la fuerza de irradiación de la revelación de Cristo de un modo históricamente eficaz y original, no los epígonos. Semejantes figuras son raras después de Tomás de Aquino" (o. c., 15s).

(31) Ibid., 149. Cf 19.

(32) Ibid., 200ss.

(33) H. U. von Balthasar, ¿Teología negativa?, en Teológica. Vol. 2. Verdad de Dios, Madrid 1997, 87ss. 
búsqueda primitiva de Dios por parte del hombre, Balthasar le llama "lugar primitivo de una teología negativa" y se verifica (en el discurso del Areópago: Hch 17, 22-34) como una relación radical con lo buscado, y cuyo punto de partida es la convicción y comprensión de que todo lo existente en el entorno mundano no puede ser realmente lo que se busca, pues es finito y pasajero, provisorio, y por eso debe ser consecuentemente negado. Los estudios de Balthasar le llevan a concluir que se ha dado a lo largo de la historia del pensamiento teológico una invariable certeza: ninguno de nuestros conceptos alcanzan a Dios, pues nosotros, afirma, "como recuerdan los Capadocios siguiendo a Platón, ni siquiera podemos penetrar la esencia de un mosquito" y por ello "al final sólo podemos llegar a decir lo que Dios no es" (34).

El excessus de Dios, tan presente y gravitante en el SMT de Alberto, a la vista de Balthasar pertenece a un pensamiento que apunta, como en Gregorio de Nisa, a un núcleo de autotrascendencia del ser mismo del hombre: por ser imagen, el hombre remite a un modelo inalcanzable (35). Por otro lado, la distinción clásica entre an sit, existencia cognoscible de Dios y quid sit, su esencia incognoscible, pertenece a los Padres, pero se sistematizará en la Edad Media y también concurrirá como axioma del theologicum negotium albertiniano. El teólogo se haya frente al abismo divino, abismo del Ser divino que se le escapa y que no se deja encerrar ni en un concepto ni en representación alguna. Alberto ha puesto a Dios "causa de todo" y Luz primera fuera de todo alcance, y por esta causalidad universal, su quiditas es una realidad remotísima al intelecto humano: "quid sit deus, clausum et occultum relinquitur" (36).

En este contexto nos preguntamos: ¿qué hay detrás de una búsqueda sinceramente hecha del rostro de Dios que se autorrevela como Creador y Redentor del hombre? Para Balthasar esta inquieta y universal indagación se da en un contexto más amplio: la certeza cristiana de haber sido desde siempre encontrados por el Dios de la revelación (así los salmos, san Agustín, Máximo el Confesor (37)). El misterio del Dios infinito e inefable es el misterio de un Dios que nos busca para salvarnos en aquella paradojal distancia, pues es a la vez absoluta cercanía de Quien se autodona como amor. Por ello es que la teología respira este aire que la purifica y la sumerge en un espacio en que gravitan las aparentes antinomias tan propias del conocimiento y de la experiencia mística: Dios es cercano y remotísimo, oscurísimo a la vez que luminoso, conocido en tanto que desconocidísimo. Por otra parte, la teología negativa sería el espacio perfecto para acceder al Dios oculto, puesto que el diálogo nunca se da entre dos miembros ontológicamente equiparables, sino que sólo es dable como una especie de 'transformación de toda criatura en un 'ecce ancilla' ante el misterio del incomprensible amor del Dios que se desposee de sí mismo" (38). Y esto no es posible desde una plataforma puramente humana, autosuficiente, sino que todo acto teológico,

(34) Ibid., 87.

(35) Ibid., 99.

(36) Cf SMT I, 453, 20-25.

(37) Transcribo aquí la hermosa afirmación de Máximo el Confesor traída a colación por Balthasar (o. c., 103): "En ningún caso se puede alargar el alma hasta el conocimiento de Dios, si Dios no se abaja primero hasta ella para elevarla hasta él. Pues el espíritu humano nunca tendrá la fuerza suficiente para correr con el fin de captar algo de la luz divina si Dios no atrajera hacia sî" (Capita theologica et oecumenica, $1^{a}$ Centuria 25: PG 90, 1093-1096).

(38) H. U. von Balthasar, B. ¿Teología negativa?, en o. c., 121. 
en cuanto acto creyente, trasciende y lleva a su total culminación el acto filosófico respecto del ser. Hay que decir, contra Heidegger que afirmaba que la teología cristiana habría abandonado el ser para caer en el ente, que el acto de fe se da respecto del Ser mismo que desvela su rostro oculto en cuanto se nos muestra y da como amor trinitario, y si bien este misterio lo es en sentido estricto, no es menos cierto que él mismo ilumina el misterio del "por qué el ser es lo que es y se nos manifiesta como luz y verdad, bondad y belleza" (39). La fe deviene, entonces, en una experiencia del ser y la teología es búsqueda del fundamento último de todo ser, es decir, Dios.

El teólogo suizo también nos ofrece un interesante y penetrante análisis de los "sentidos espirituales" (40) que ahora nos resulta útil. Los órganos de la experiencia místico-intuitiva de Dios son los llamados "sentidos espirituales", doctrina que pasa por distintas fases históricas. En la fase medieval son las afirmaciones de Guillermo de St. Thierry las de mayor peso, según estudios de K. Rahner (41). "Ver", "oír", "gustar", "tocar" y "oler" del alma que ama a Dios son expresiones de esta doctrina en cuanto en el acto místico se da una forma de "saboreo", en el sentido del "sapor" de la "sapientia" de la que es objeto la mens en sentido agustiniano (la misma mens albertiniana, sin duda), ápice del alma en cuanto facultad íntima y central con la que podemos "tocar" y "sentir" a Dios, "gustándolo" o "saboreándolo" en una innegable oscuridad de su inmediatez. Por otra parte, este "contacto" del alma con Dios que nos explica Balthasar tiene su propio lugar en el SMT de Alberto Magno (42). En la cima (vertice) de la contemplación el intelecto, es decir, la mente (mens) recibe una iluminación de lo alto (desuper) de la más sublime claridad, claridad que llena de manera eminente la mente de los que son encandilados, y en este acto de máximo contacto la mente es deificada e iluminada.

Balthasar no deja de mencionar que el acto de fe que comporta el acto contemplativo se da bajo la forma de la "pasividad" -dimensión muy explícita por cierto en la doctrina neoplatónica dionisiana presente en el SMT (43)-, es decir, la recepción gratificante que sitúa al hombre, gracias al hecho de la revelación divina, frente a la

(39) H. U. von Balthasar, Elementos de la forma de la fe, en Gloria. Una estética teológica. Vol. 1. La percepción de la forma, Madrid 1985, 147s.

(40) Cf H. U. von Balthasar, Los sentidos espirituales, en Gloria. Una estética teológica. Vol. 1. La percepción de la forma, 323-375.

(41) Balthasar cita aquí el estudio de K. Rahner: La doctrine des 'sens spirituels' au moyen-âge en particulier chez S. Bonaventure, en RAM 14 (1933) 263-299.

(42) Afirma Alberto en SMT I, 457, 24-35: “...verticem, dico, facientem desuper splendere in mentem superclarissimum quoddam [...] tamen ex hoc quod attingimus aliqualiter ipsam relictis omnibus, mens deificatur et illuminator..."

(43) En la exégesis albertiniana de las obras de Dionisio se revela una total asimilación de ciertos conceptos neoplatónicos armonizados en la doctrina sobre la fe. Así es como en SMT I, 458, 54-62 trae a colación un pasaje central de los Nombres de Dios (II, 648 A-B: en Obras Completas, 287s; Corpus Dionysiacum, I, 133s) en que explica Dionisio el lugar que tiene la experiencia personal en la adquisición del conocimiento de los misterios divinos (Encarnación sobre todo): Hierotheo, más que por estudio teórico obtuvo este conocimiento por "experiencia personal", pues disfrutaba de "cierta connaturalidad con estos temas", es decir, "se identificaba" con ellos, y esta connaturalidad o identificación interior por la fe es lo que el lenguaje platónico llama $\sigma v \mu \pi a ́ \theta \epsilon \iota a$, compasión o simpatía. Esta es, entonces, una propiedad de la fe como abandono en la revelación divina, lo que marca al theologicum negotium en cuanto ciencia de los misterios divinos bajo el signo de la receptividad. Cf D. Acuña Burgos, o. c., 104-107. 
supremacía infinita de Dios, de su mismo ser (44). De hecho, el acto de fe implicado en la contemplación postula un a priori teológico entendido como el fundamento de la instrucción interior del alma procedente del exterior. Y en este punto Balthasar se muestra conforme con la doctrina agustiniana de la iluminación del Magister interior también integrado por Alberto en la explicación del alumbramiento de la verdad divina buscada por la mente del auditor de la teología mística (45). En fin, en este acto de plenitud gnoseológica (y de alguna manera ontológica) que es la fe la luz del ser en la que se conoce todo ente se nos otorga profundizada y elevada en la lumen fidei, pero no como si se tratase de la visión de la cosa misma, es decir, de la intuición de Dios y sus misterios, experiencia reservada a la vida eterna, aun cuando la fe comprometida en su totalidad en la contemplación en cuanto abandono a la luz recibida es quaedam inchoatio visionis, o sea que la vida eterna ha comenzado ya en la vida de la gracia (46).

Entendida la fe como luz concedida gratuitamente, a Balthasar no le es difícil extraer algunas consecuencias para el quehacer teológico (47). Una primera exigencia es la de no cegar la visión a la luz propia de la fe en el sentido del a priori teológico de la obediencia a aquella luz irradiada en la que precisamente creyendo y no viendo se participa en la sabiduría del Dios que se autorrevela. Quien mayormente de manera obediente piensa la fe, en esa misma medida verá. Y se sabe que la acogida plena de la fe produce el hombre integral (dimensión ética): esto significa que "el hombre pensará correctamente cuando las proporciones de su pensar y obrar igualen, en virtud de la gracia, las del objeto de la fe marcadas por Dios". Y ya que el Dios trino es el objeto formal de la teología, la Trinidad "debe hacerse visible en todos los desarrollos y articulaciones concretas y particulares de la teología” (48). Esta punta del pensamiento balthasariano ahora penetra más profundamente para hacer brotar una segunda consecuencia lógica: la gnosis derivada de la pistis es propiedad del cristiano que puede convertir su acto radical de fe y de obediencia a la luz divina, en norma de su vida entera y en tanto acto radical de la fe se describe un tipo de comportamiento determinado por Dios en unas relaciones gratuitas. Esta gnosis o conocimiento teológico es propia del santo cristiano y la encontramos configurada -aunque en aquel momento faltaba contar aún con categorías existenciales y personales más centralessobre todo a partir de las doctrinas de san Agustín y san Bernardo de Claraval que miraban la tarea teológica con categorías más bien voluntaristas y afectivas que puramente intelectuales y teóricas.

(44) H. U. von Balthasar, Elementos de la forma de la fe, en Gloria. Una estética teológica. Vol. 1. La percepción de la forma, $145 \mathrm{ss}$.

(45) Cf SMT I, 456, 30-38.

(46) La distinción de los estados de visión está claramente afirmada en las cuestiones complementarias que el doctor universalis plantea luego de haber entregado la significatio al pasaje de la subida o ascensión de Moisés (SMT I, 461, 71-462, 38). Alberto afirma: “...en la patria (in patria) Dios es visto en su esencia, mientras en la contemplación en el estado peregrino (viae) es visto en los efectos de la gracia y de la luz que desciende en ella. De nuevo, en la patria, la visión de Dios será liberada perfectamente de toda miseria, que no se da aquí, y de nuevo será por el hábito de la gloria, aquí, sin embargo, por el hábito de la gracia” (I, 463, 27-33, en edición de A. Meis, 77).

(47) Cf H. U. von Balthasar, o. c., 153-156.

(48) Ibid., 154. 
Balthasar anuda su pensamiento al afirmar que la unidad descubierta entre teoría y praxis de fe ha cristalizado históricamente en lo que llama "teología de los santos". Esta teología viva, en cuanto existencia de fe comprometida, presente en algunos períodos de la historia de Iglesia, especialmente en la Patrística, puede ser definida como una especie de confirmación de lo enseñado por lo vivido. En el ensayo titulado Teología y santidad, explica cómo hasta la Escolástica muchos de los santos preponderantes fueron también grandes dogmáticos y su influjo se apoyaba en que el concepto pleno de la verdad ofrecida por el Evangelio consiste precisamente en esa manifestación viviente de la teoría en la práctica, del saber en el obrar, vale decir, que no se da, pues, en el sentido de la revelación, ninguna verdad real que no deba ser encarnada en una acción. Por eso en los grandes doctores de la Iglesia es realmente posible que la verdad que enseñan los que la escuchen puedan reconocerla y verificarla inmediatamente por su 'caminar en la verdad'. Ahora bien, quien representa un hito para esta fusión armoniosa es el Areopagita, quien se ve persuadido de sostener que sólo el que es 'luz del mundo' puede difundir esclareciéndolas las cosas santas. En efecto, en la Jerarquía eclesiástica el orden jerárquico eclesial se construye sobre un gran a priori de la identidad del ministerio y santidad, doctrina que con el correr del tiempo sería tradicionalmente aceptada.

Concluimos. Se ha visto como para el Comentario del santo obispo coloniense el ascenso místico propuesto por Dionisio como gracia es el supremo sentido de todo quehacer teológico. Esta vía es una forma especial y arquetípica de ciencia, puesto que el intelecto se ve atraído e iluminado por Dios, Causa omnímoda y principio de toda bienaventuranza. El theologicum negotium es un esfuerzo piadoso en sentido agustiniano y la oración es la condición no sólo de la obtención de sus frutos, sino de su misma autenticidad, armonizándose en su dinámica interna el carácter noético y el carácter ético-espiritual.

Motivados por la reflexión balthasariana nos preguntamos si el ejercicio de la ciencia teológica hoy está dando espacio a esta armonización tan viva en tiempos del san Alberto Magno, para quien la teología comporta una vía mística. La conjunción entre lo dogmático y lo ético-espiritual, aquello que podemos llamar ethos del quehacer teológico, recuerda Balthasar (49), ha sufrido posteriormente a la Escolástica un verdadero divorcio, pues Alberto Magno, Buenaventura, Tomás de Aquino y otros no permitieron nunca que su comprensión de la verdad fuese desviada del recto camino enseñado por la lumen fidei como consecuencia de la gran cantidad de verdad filosófica que afluía a ellos. La "teología de los santos" es la que brota de la doctrina y la vida de los que el teólogo suizo llama teólogos "totales". Este tipo de teólogos y su consiguiente teología es la teología de la recepción y la obediencia al Espíritu, y por eso esta teología se da como actitud orante que finalmente culmina en un acto de adoración (50), cualidad que está más allá del sistema, bajo la forma de aire que

(49) H. U. von Balthasar, Teología y santidad, en o. c., 242ss.

(50) Comparando las teologías filosófica y teológica, Balthasar afirma: "al final de una teología filosófica negativa se encuentra el 'silencio', porque las flechas de todos los conceptos y palabras caen al suelo antes de alcanzar el blanco, así también al final de la teología cristiana se encuentra otro silencio: el de la adoración, a la que le falta la voz, asimismo, debido a la desmesura del don” (¿Teología negativa?, en o. c., 106). 
lo llena todo o atmósfera en que se baña. La oración, por tanto, es la "única actitud objetiva ante el Misterio divino", en que se espera todo y el corazón no se anticipa a la revelación del amor de Dios. En este sentido podemos entender que Alberto Magno plantee la necesidad de que el theologicum negotium sea affectivum, haciéndose así justicia al tema único e inefable que está comprometido.

En fin, Balthasar reconoce en los santos doctores de los primeros siglos de la teología la llamada teología "orante, arrodillada", y en Dionisio al "maestro del respeto teológico", en cuanto ejemplo de "unción" fecunda y trascendente en el tiempo. Pero hubo un momento en que de una "teología de rodillas" se pasó gracias a la llamada "teología científica" a una teología "sentada" que no logra verse plena de auténtica unción. Pero tampoco pensemos que la propuesta balthasariana es desandar la historia y cegarse ante los innegables avances de un perfeccionamiento del método y la racionalidad teológica, sino más bien que el progreso se realice también gracias a un más valiente y profundo diálogo con las fuentes no sólo escriturísticas sino sobre todo patrísticas. En efecto, en la teología patrística se vislumbra una reflexión guiada por la "certeza secundum pietatem", cuya evidencia es superior a la ratio, a tal punto, que si un santo es matemático -aquí cita Balthasar a Alberto Magno- "antes que negar la verdad de la fe, negaría que la suma de los tres ángulos de un triángulo es igual a dos rectos" (51).

(51) H. U. von Balthasar, Elementos de la forma de la fe, en o. c., 150. 
